\title{
PLACE-MAKING: AN APPROACH TO THE RATIONALE BEHIND THE LOCATION CHOICE OF POWER PLACES. IOWA STATE UNIVERSITY CAMPUS AS CASE STUDY
}

\author{
Alenka Poplin ${ }^{1}$, Claudia Yamu ${ }^{2}$, Luis Rico-Gutierrez ${ }^{1}$ \\ ${ }^{1}$ Iowa State University, Ames, Iowa, USA (apoplin@iastate.edu, lrico@iastate.edu) \\ ${ }^{2}$ University of Groningen, Groningen, The Netherlands (claudia.yamu@ rug.nl)
}

keywords: power places, mapping, volunteered geographic information (VGI), configurational accessibility analysis

\begin{abstract}
This paper concentrates on power places as perceived by the students in a 60,000 people college town in the United States. Power places are favourite outdoor locations that evoke positive emotions, and are conducive to relaxation and reduction of stress. Further understanding how location affects those places and the feelings of students will help planners and designers be more intentional as they create conditions favourable to the development of cities that are healthy, sustainable, resilient and smart. Research methodologies used in this paper include empirical cartography, mapping and space syntax. We conclude the paper with a discussion of the presented results and further research directions.
\end{abstract}

\section{INTRODUCTION}

Involving youth, students and marginalized, underrepresented populations into urban planning processes has long been a challenge, yet these individuals are among the most crucial to engage as cities seek to foster the next generation of decisionmakers and contribute to the creation of more equitable, resilient and connected communities (Shenk, Anderson et al. 2016, Shenk, Krejci et al. 2017). Often students move to different cities to continue their education and are mostly focused on their studies rather than on getting involved into the co-creation of the cities and environments in which they temporarily live.

We are interested in how students perceive their environment. The goal of this paper is to research how students feel at certain places and how they describe them. We particularly focus on power places, which are defined, for the purpose of our research, as places in which people recharge and feel at peace or exuberance, places that evoke positive feelings (Poplin 2017). We selected the Iowa State University (ISU) campus and the city of Ames as our case study because in many dimensions represents typical conditions of a North American, Midwestern university town.

A map-based survey enabled us to capture and explore different characteristics of power places as perceived by the students. In the future, we will expand our methodology to include the use of a volunteered geographical information (VGI) system offered online. Through this kind of mapping, we aim to contribute to discourses on place awareness, its cognitive basis, and emotional implications. The analysis of power places is combined with a space syntax analysis of the city of Ames and the Iowa State university campus (Hillier and Hanson 1984, Hillier 1996). Space syntax is a theory and method that links quantitative descriptors of urban layouts to different social, economic and cognitive factors (van Nes and Yamu 2017 (in print)). The representational nature of this methodology is conducive to developing associations between intuition and science. It can also be used to design and plan cities, as well as in research (Hillier 2009).
Improved understanding of the impact of location and urban configuration on power places, their characteristics, and emotional manifestations, can help designers and planners better understand public space in cities, and promote conditions that support sustainability, liveability and resilience. In addition, it will contribute to debates in GIScience related to place-based GIS (Goodchild 2011, Winter and Freksa 2012) and questions relevant to research in digital cartography, specifically on how to represent places and emotions in a geographical information system (GIS).)

The novelty of herein presented ongoing research project is to combine emotions mapping with configurational analyses which can contribute to the understanding of place-making, and add to the debate on smart cities and big data. This paper summarizes our research results.

\section{DECISION-MAKING AND PLACE ANALYSIS CONTRIBUTING TO PLACE-MAKING}

\subsection{Engaging youth and students into planning}

Engaging youth into urban planning has recently gained more attention among researchers and practitioners. It is difficult to engage youth in different stages of planning processes and the co-creation of cities and neighbourhoods. For the most part, youth are usually not present in municipal and community decision-making and are often overlooked in urban planning processes. Typically, landlords, business owners, public officials, developers and other stakeholders possess more power and authority and get more access to urban planning processes. This approach affirms hierarchical relationships that privilege leaders and public officials over youth and residents in general.

To our knowledge, there are no official urban planning mechanisms that specifically involve students specifically into the co-creation of the places in which they live. Integrating the voices of youth into city and neighbourhood decision-making as well as the use of transdisciplinary scientific research is crucial for developing forward-thinking planning and research related to sustainability (Shenk et al. 2016, Shenk, Krejci et al. 2017) 
Socially just, intergenerational urban spaces should not only accommodate children and adolescents, but engage them as participants in the planning and design of welcoming, pleasant and happy places (Derr et al. 2013).

\subsection{Research on favourite places and place attachment}

How do people in general and youth in particular perceive and experience places in their neighbourhood? What is important to them? Knowing more about the qualitative and quantitative attributes of places and people's perception of them may enable professionals to design more sustainable, pleasant, happy and therefore smart places. Korpela and Hartig studied favourite places (Korpela 1992, Korpela and Hartig 1996, Korpela 1998, Korpela, Hartig et al. 2001, Korpela 2012) which they define as places that afford restorative experiences and may aid emotional and self-regulation processes. In their initial studies, they worked with young people, especially with adolescence. They asked them to compose an essay describing their favourite places. Adolescents reported going to their favourite places to relax, calm down and clear their minds. They also described the experience of beauty, freedom and escape from social pressures. Natural settings such as parks, proximity to water and green areas were over-represented among favourite places and underrepresented among the unpleasant places. Adolescent participants reported the reduction of anxiety, fears and social pressures while being at their favourite places. The research conducted by Korpela and Hartig $(1996,2001)$ provides indications that there is a link between favourite places and restorative experiences.

Francis and Cooper-Marcus (1997) asked college students to write essays about a time when they were feeling low or depressed, and then went to a particular place to lift their spirits or gain relief. They also concluded that natural settings in cities provide restorative experiences that serve emotional purposes and self-regulations. The experiences reported by students when they visited these places included "attaining a state of calm or balance" and thinking through or gaining perspective on problems (Cooper-Marcus 1997)

\subsection{Public Participatory GIS (PPGIS)}

Public Participatory GIS has been extensively discussed since the mid-1990s and represented at that time a novel idea in which GIS was used as core technology, extended by additional public participatory functions (Schroeder 1996). Public participatory operations were built as add-ons to the GIS system, enabling citizens to post comments on existing plans using online interactive maps, store those comments in a geospatial database, chat with other participants in the process, or just comment on what others suggested (Kingston et al. 1999, Kingston, Carver et al. 2000, Carver 2001). In some cases, the citizens may send their annotated maps to the planning authority (Steinmann, Krek et al. 2004) or leave their comments directly on the online maps.

PPGIS enabled, for the first time, a two-way online communication based on online interactive maps. Some of the pioneering researchers in PPGIS include (Pickles 1995, Schroeder 1996, Rinner 1999, Talen 1999, Kingston, Carver et al. 2000, Al-Kodmany 2001, Basedow and Pundt 2001, Carver 2001, Jankowski and Nyerges 2001, Craig, Harris et al. 2002, Schlossberg and Shuford 2005, Georgiadou and Stoter 2010). Sieber (2006) provided a thorough overview of the contributions of different researchers in this subject area, looking back at more than fifteen years of research.
Positive aspects of PPGIS include the unique opportunity to enable the spatial visualization and analysis capabilities inherent in GIS to enhance citizen involvement in public policy and planning issues (Schlossberg and Shuford 2005). Other advantages are related to its ability to collect data online, store it in geospatial databases, and enhanced process and analysis when compared to data that is collected using traditional methods in public meetings (Kingston, Carver et al. 2000) or with the plans presented on paper. Critics report difficulties using PPGIS applications online, especially when they intend to attract a broader, very heterogeneous groups of users/citizens (Thompson 2000, Basedow and Pundt 2001). These problems have been addressed in research that deals with usability of PPGIS applications and their suitability for civic engagement and participatory processes in urban planning (Haklay and Tobón 2003, Steinmann, Krek et al. 2004, Poplin 2012; 2015).

\subsection{Volunteered Geographic Information (VGI)}

Development of mobile devices such as smart phones and tablets lead to novel ways of collecting geographic data; in which information can be collected on the go, directly immersed in the situation where changes in the environment have been observed. Goodchild writes about the citizens acting as sensors (Goodchild 2007a, Goodchild 2007b, Goodchild 2007c) contributing data to GIS-based systems that are often freely available online and/or on a variety of mobile devices. He coined the term Volunteered Geographic Information (VGI).

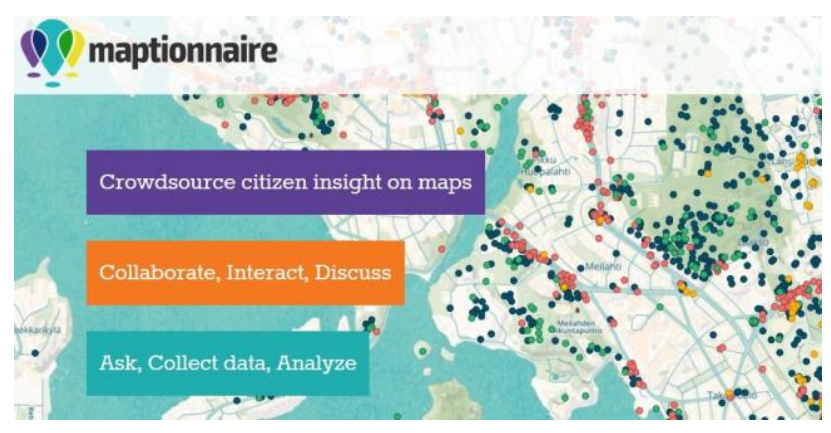

Figure 1. VGI platform Maptionnaire

In a VGI environment, the user contributes her/his knowledge about the environment and is able, through user-friendly interfaces, to enter this information/knowledge/data into the system which stores it in a geographic database. VGI uses the same structure of storing objects as a GIS and can relate this graphical data with other attributes describing the characteristics of the objects. A VGI-based application may enable different forms of spatial analysis, but often it does not. It is mainly designed as a data collection method offered on a PC or on mobile devices such as smart phones and tablets. An example of a VGI is Maptionnaire (https://maptionnaire.com) which combines GIS-based maps and an online questionnaire. It further allows some simple analysis of the collected data. This idea of combining questionnaires and maps has been previously developed and tested by Poplin (2012). Maptionnaire includes simple sketching and drawing; drawing polygons seems easy but true sketching capabilities are not yet implemented. The current version concentrates mostly on crowdsourcing, online data collection and citizens' engagement and includes analytical capabilities and the ability to store the submitted citizens' comments in a common geodatabase (Figure 1).

A map-based questionnaire will be designed, developed and implemented for future stages needed in this research endeavour 
addressing the specific needs of students involved into this ongoing research project. The implementation will first be tested with a small group of student users and will be later implemented to attract as many responses of ISU students as possible. The advantage of Maptionnaire is that it stores the entered data in a geographical database. Further, this data can then be used for a variety of spatial analysis, spatial queries and statistics.

\subsection{Space Syntax}

This method consists of calculating configurative spatial relationships in built environments. It addresses the relationship between physical elements of a city and its social activity pattern of utilization (Yamu and Voigt 2011).

Space syntax demands four elements in urban analysis. Firstly, space syntax means operating with a concise definition of public urban space, understood as a social space which is open and accessible to people. Secondly, it offers a family of techniques for analysing cities as networks of spaces formed by the placing, grouping and orientation of buildings. Thirdly, it involves a set of techniques to observe how these networks of open space relate to functional patterns and even social wellbeing and malaise. Fourthly, based on the empirical results arising from the first two aspects, space syntax makes it possible to develop a set of theories about how urban space networks relate to the social, economic and cognitive factors which shape them, and how they continue to be affected by them (Hillier et al. 2007). The advantage of using space syntax techniques is that we can identify urban configurations and processes that may have the same properties at different scales, from the neighbourhood to the region, e.g. path, street, highway. This self-similarity across scales allows an in-depth understanding of how a city and a place functions (Yamu 2014).

Space syntax describes and quantifies how easy is to access and navigate any space using a mathematical street network model. It measures two major all-to-all relations of street segments based on the idea of centrality: movement (Integration), or the potential for integration of each street segment with respect to all others, and through-movement potential (Choice or Angular Segment Analysis) of each street segment with respect to all pairs of others. Integration measures the topological distance from each street segment to all others within a certain radius. In other words, how many turns must be taken from a street segment in order to reach all other street segments? Integration arguably predicts the use of a street; the easier its accessibility, the more integrated and thus the more popular a street is. In contrast, Choice measures the frequency of how likely a street segment is part of a particular path between all possible pairs of start- and end points within a certain radius ('route choice'). It indicates how often, potentially, a certain street segment will be used for a journey within an urban system. In this paper, we mainly focus on the potential throughmovement. The constitution of centrality works through spatial configuration on route choice within a street network. These factors influence land use and location choices.

Space syntax as a static street network model indicates dynamics; it is simple but robust allowing for a quick syntactical analysis of a range of cases (Yamu 2014). While the method can be applied to explain the physical configuration of places - from cities to neighborhoods, and also university campuses (Yaylali-Yildiz, Yamu and Cil 2013) - the results of the spatial analysis must be connected to our understanding of societal processes and human behavior (van Nes and Yamu (in print)).

\section{RESEARCH FOCUS}

\subsection{A broader research agenda}

A broader research agenda, which is the basis for this article, includes studying places, particularly power places, and placemaking, with a special focus on participatory place-making. Knowing how citizens feel about places and where in the city they experience positive, uplifting, restorative emotions will help planners and designers to create pleasant, healthier, resilient and sustainable cities.

More specific research questions include:

- Where in the city people experience positive feelings (power places) and how do they describe these feelings? We focus on emotions linked to power places.

- How do people describe power places, what is important to them and what do they notice about these places? We are particularly interested in the physical characteristics of these places.

- What research methodologies and tools can better capture descriptors of power places and improve our understanding of them?

- Which modelling and analysis techniques can be used for spatial analysis of these places?

The goal of this paper is to study power places in a selected study area around Iowa State University in Ames, Iowa. We explore the capabilities of two selected methodologies implemented in our research: the first one was used to capture power places with the help of a mapping technique; the second (space syntax) enabled additional spatial analysis of the selected area.

\subsection{Case study Ames: the scale of the city and the scale of the university campus}

For this project, we focused on the City of Ames, Iowa, particularly the Iowa State University campus. The city of Ames has a population of approx. 60,000 inhabitants, of which about 36,000 are students and about 15,000 are university employees. Figure 2 shows the city of Ames coloured in grey. Figure 3 takes a closer look into the campus area and its spatial structure. Both figures serve as a geographical orientation for these two different scales of representation.

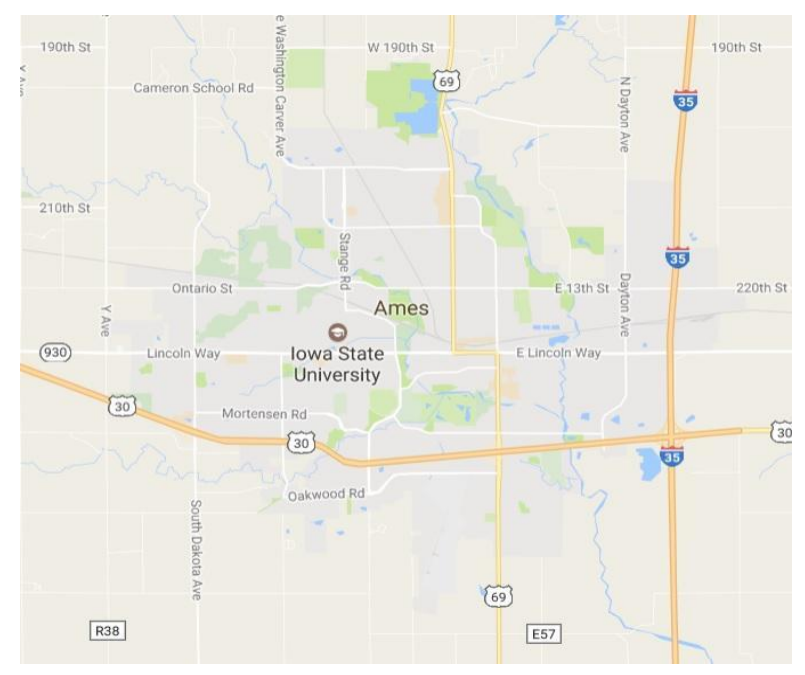

Figure 2. The City of Ames area, Iowa 


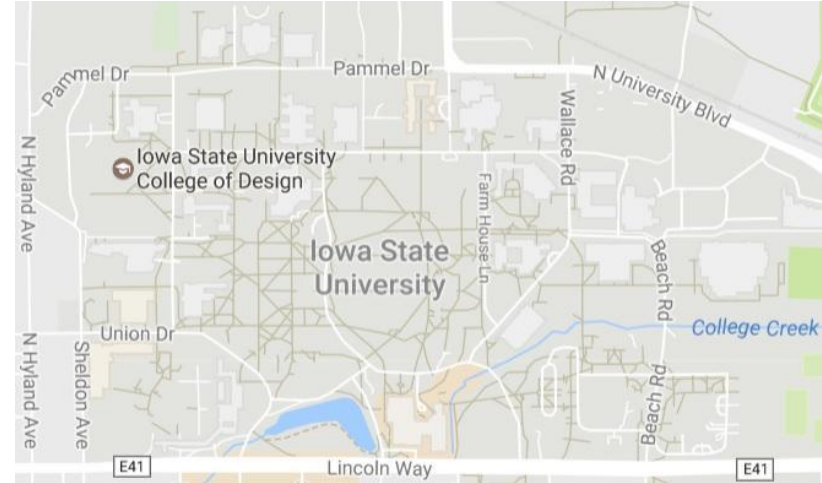

Figure 3. ISU campus area, Ames, Iowa

The investigation on power places takes the whole city into account and looks into individual power places reported by the students. In addition, a space syntax analysis was carried out for the whole City of Ames with a zoom-in on the university campus area in order to understand the rationale of location choice for power places by the students. The majority of power places can be found in close proximity to the Iowa State University campus (Figures 4, 5). The following two chapters explain the research methodology for mapping power places and the space syntax analysis.

\section{MAPPING POWER PLACES}

\subsection{Power places: definition and research objective}

In this empirical experiment conducted with the students from Iowa State University, we focused on power places ("Kraftorte" in the German language). A power place is defined as a place in which people recharge and feel at peace or exuberance, a place that evokes positive feelings. We look at these places from the perspective of students living in Ames. We explore the locations of these places and their physical characteristics; how people/citizens express themselves when they talk about particular places in the city in which they live; which words do they use to describe them and to describe the emotions they feel at these places. Power places are selected by participants, and represent their personal choices. We focus on students and their perceptions of power places.

\subsection{Research methodology}

Our research is empirical, based on a set of experiments with paper maps accompanied with a questionnaire. It is based on the methodology used in our first experimental endeavour conducted in the City of Hamburg, Germany (Poplin 2017) in which we collected 191 power places.

In our research in the City of Ames, Iowa, we used the same questionnaire as in our previous research and a paper map designed for the needs of the experiment in Ames. In the questionnaire, we first defined power place, explained the concept and asked participants to follow specific instructions. The instructions asked the participants to mark their personal power places on the paper map and describe them in the survey. The description included up to four characteristics of the place (describe the place with your own words) and up to four words describing emotions felt at these places. Participants also had space available for a sketch of their identified power place. We also asked how they usually get to their power place (by foot, bike, public transportation, etc.). At the end of the survey, we collected basic data about the participants which included their age, gender, and time spent in Ames.

\subsection{Power places in Ames: collected data}

The participants in our initial study, which can be considered our pilot study, were students of Iowa State University. We collected 40 filled out questionnaires and gathered 75 power places selected and described by the students.

We inserted all power places as point features in a geographic information system (GIS) and displayed an aerial photo as a background (Figure 4). Power places are indicated as red dots and one can see their concentration in particular areas of the city. The two more dense locations are Ada Hyden Park and its lake, in the north part of the city, and Campus Town, south-west of the University campus (Figure 4).

Figure 5 displays the relation of power places, their locations and the locations of green areas/parks in Ames. One of the most interesting results is that the majority of the power places do not lay in the many parks available in the city. The only green area considered to be a power place for several students is Ada Hyden Park in the north part of the city. A small concentration of power places is visible in Lee Park, close to the university campus on the west side. Ada Hyden Park, for example, offers a generous parking lot, which facilitates access by car to enjoy this power place. Our assumption is that the location of power places is related to the availability of parking areas in close proximity, and their accessibility by public transportation and walking. The second concentration of power places can be found in the central campus area, close to the landmark buildings or features. We need to add that we are in the process of collecting additional data; the current data is rather small. We aim at conducting an additional survey in a more controlled environment to add more data about power places which will enable us to better understand their relationship with the green areas in the city. Additionally, a space syntax analysis with a particular focus on connectivity and a pedestrian model may also help to improve the interpretation of these results.

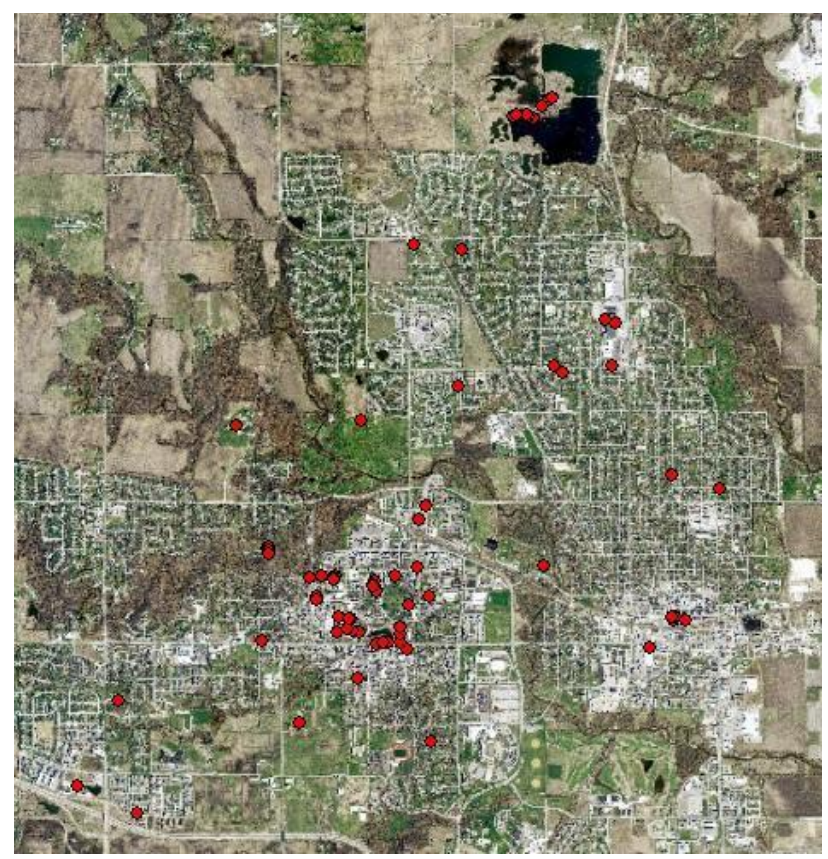

Figure 4. The location of power places in Ames, Iowa 


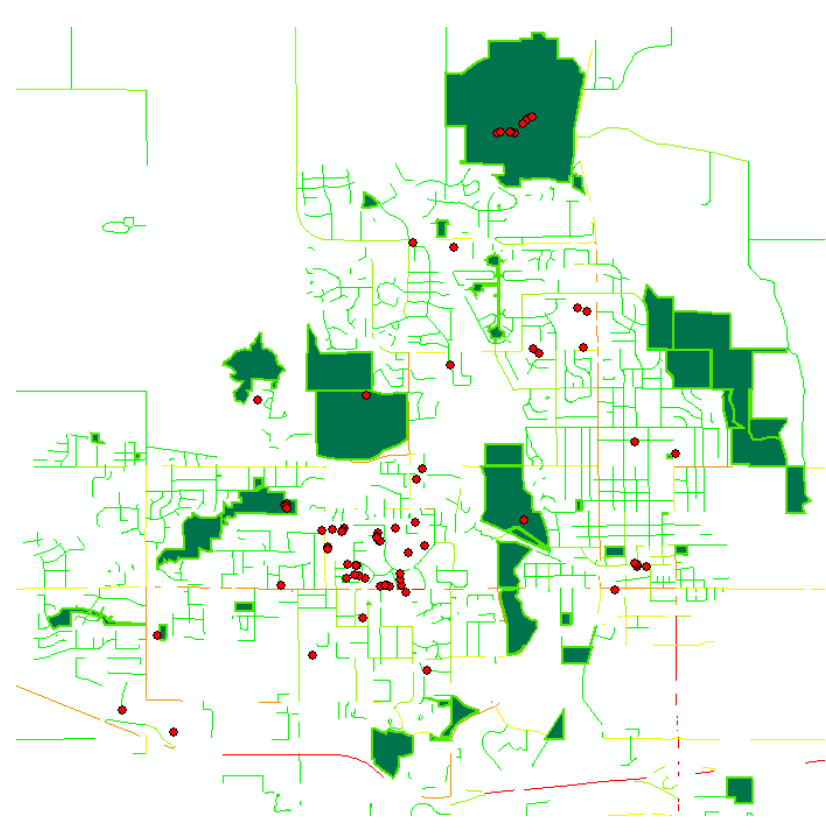

Figure 5. Power places in Ames in relation to green areas

Besides collecting the locations of the power places, we also gathered additional information about them. Additional data included words describing each specific power place and words describing how students feel at these places. The students at Iowa State seem to appreciate places that include the following characteristics: open, greenery, benches, quiet atmosphere, the possibility of sitting and walking, proximity to water, cleanliness, open spaces, calm atmosphere, and a nice neighbourhood. They also mention proximity to food options, proximity to the malls and other shopping options, and proximity to their home.

The main emotions reported in the power places listed by ISU students included: happy, inspired, relaxed, quiet, calm, optimistic, serene, exciting, comfortable, making peace with myself, secure, rewarded, overwhelmed, warm, love. They also mentioned that they feel energized, amazed, tranquil, refreshed, philosophical, sleepy, and alive at their selected power places.

\subsection{Uncertainty in defining places}

In reviewing the responses given on the map and in the questionnaire, we can observe the difficulty in placing a point for a place. Places as perceived by the citizens very often do not have clear borders and do not have a very precisely defined location. The mapping of places presented in this paper was reduced to a single point in order to be able to insert them into a geographical information system (GIS).

The description of a place cannot be reduced solely to its objects, but also must contain descriptions of the atmosphere felt at these places. The experience at these places was very important to the participants. Goodchild 2011 (p. 1) claims that there is a "fundamental tension with the informal world of human discourse, and nowhere is this more apparent than over the vague concept of place." He calls for additional research on place-based GIS and explores this tension from various perspectives: current methods of geographic representation in digital form, inherent ambiguities, the case of the gazetteer, the role of volunteered geographic information, and place as an expression of context (Poplin 2017). Winter and Freksa (2012) support these claims and go even a step further in stating how important it is to capture the "human cognitive notion of place" in order to attain a "smooth communication between human users and computerbased geographic assistance systems."

There is inherent uncertainty when trying to find the exact location of the reported power places from the paper map, which is combined with the uncertainty of finding and defining the exact location experienced by the participants in the survey. Using online interactive mapping tools such as Maptionnaire (maptionnaire.com) may help to reduce at least one of the uncertainties related to transferring the power places indicated on the paper map into the digital format. However, this method may not help to solve the issue that stems from not having clearly defined borders as required by a GIS model. Further research is needed on mapping places in GIS and the need to establish a place-based GIS.

\section{SPACE SYNTAX ANALYSIS}

\subsection{Configuration of the city in correlation to the location of power places}

As stated in our broader research agenda, using space syntax is a first step in understanding the rationale behind the location of the identified power places. In particular, our endeavour is to shed light on a new aspect of a socio-spatial analysis linked to the configuration of space and to better understand the choices made by participants to designate individual power places close to the university campus and the built environment of the city.

The collected data highlights among many characteristics that students appreciate proximity to shops, food options, and home. Further, walkability was an important factor next to greenery, open spaces and cleanliness equipped with urban furniture and infrastructure. The preferences show that inter alia proximity and centrality are important factors. This is related to the scale of the analysis. For example, walkability is linked to the scale of neighbourhoods. Walkable neighbourhoods are an important element of a sustainable community ("access for all") as this softtransportation mode is independent from income and contributes to a healthy, liveable, and smart city.

For the space syntax analysis, we chose two scales: a citywide scale and a neighbourhood scale. We aim to address microeconomic functional patterns of the residential space with its spatial cultures and walkability. Figure 6(a) depicts the citywide scale representing the foreground road/street network of the City of Ames. The street segments are marked in red. This citywide network gives the city its structure, highlights the main route network through the urban area, links urban centres and explains the location of micro economic activities such as the location patterns of shops. It makes the accessibility from the city centre or other centrally located places to the city edge efficient and possible. The foreground network of Ames addresses an individual motorized transport mode. For the street network analysis, we used a colour range from red to blue whereas red street segments represent high accessibility and blue street segments represent low accessibility.

The analysis in Figure 6(a) indicates that the majority of power places (marked as black dots) are located in close proximity to high accessible roads (red and orange street segments) and shopping opportunities. This suggests that walkable areas are preferable in close reach to the overall connecting route network. 


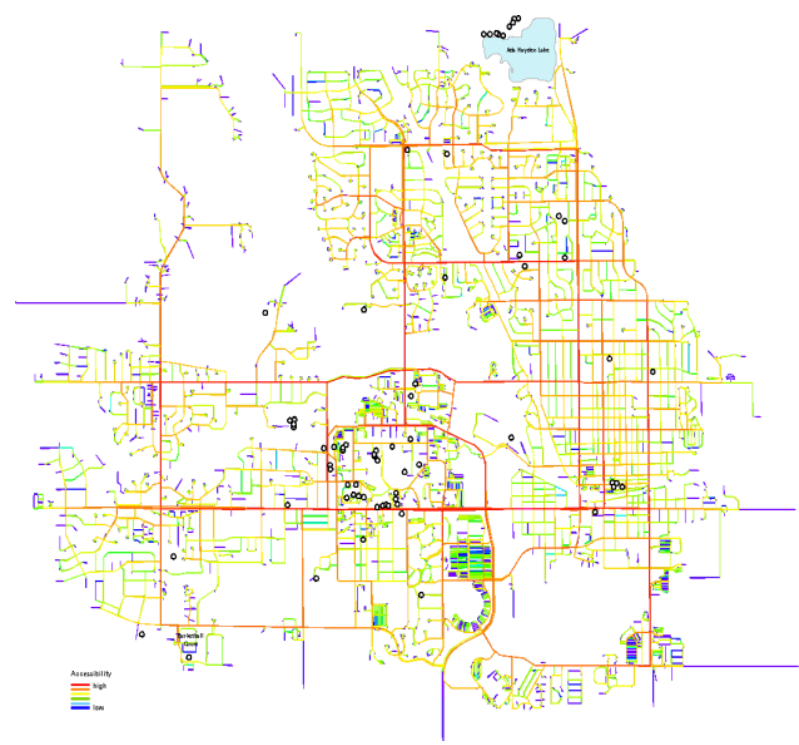

6(a) Citywide potential through movement for Ames, Iowa

Figure 6(a) shows the citywide potential through movement "Normalised Choice N" (or NACH RN). The analysis highlights that the majority of power places are in close proximity to highly accessible road networks at a citywide scale. Figure 6(b) shows a zoom into the university campus with power places.

According to Hillier $(1996,2001)$ the background network is being comprised of a foreground network of linked centres at all scales set into a background network of residential space and its cultures. The configurational analysis in figure 7(a) depicts the local scale residential areas, the city centre with its main urban shopping street and cultural district - 'Main Street' — as well as the university campus area.

The campus area is highlighted as a local highly accessible, walkable area which can be explained with university campus planning. According to Neuman (2003) university settlements started to occupy specific locations from the eighteenth century onward with an inward-focused learning community and distinct spatial organization.

In the American campus spatial model, separate buildings with courtyards gathered around in the open landscape. The campus gathers many functions in itself for the students' comfort and needs (Turner 1987). Chapman (2006) defines the campus as a 'cultural landscape' due to its deeply embedded social purposes. Social spaces have important roles and thus we find in the university campus area a connection between space and publicness.

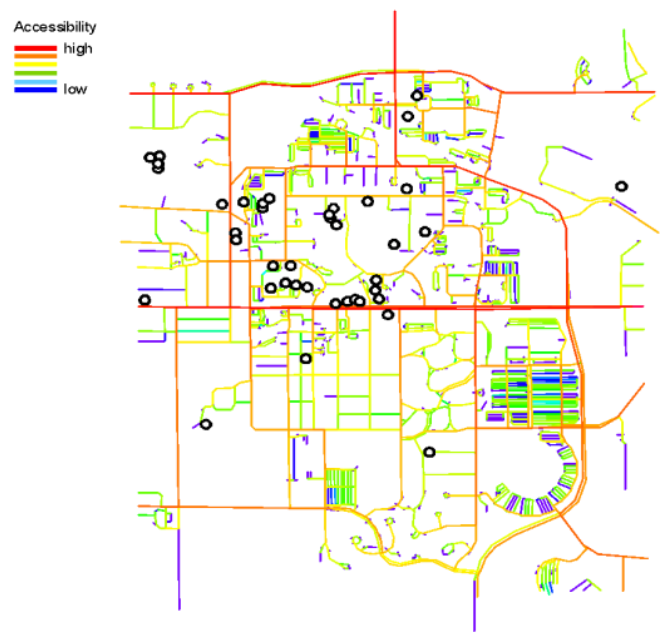

6(b) Zoom-In of the citywide potential through movement: Iowa State University Campus

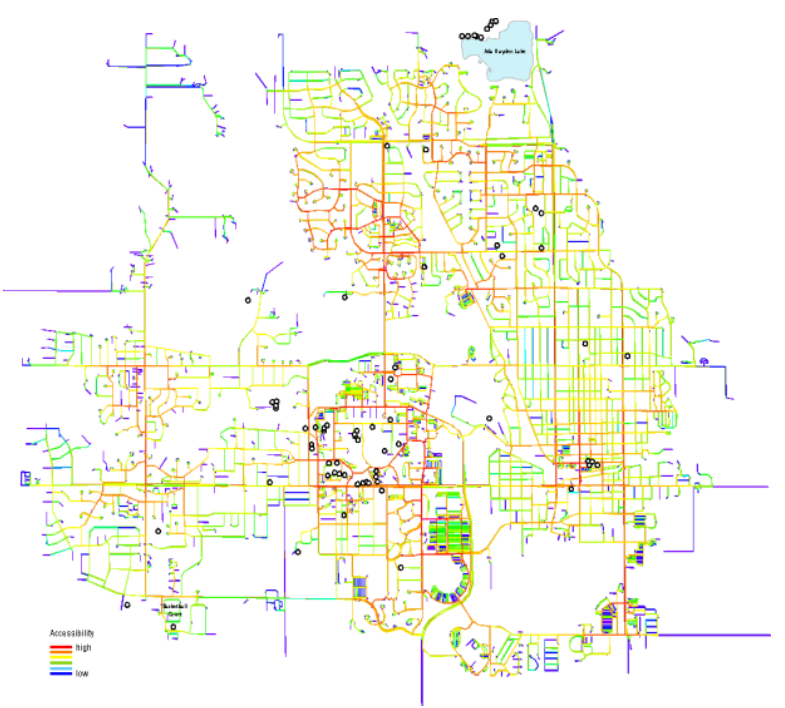

7(a) Local potential through movement for Ames, Iowa

Figure 7(a) shows the local potential through movement "Normalized Choice local" (or NACH R low metrics 10\%). Figure 7(a) depicts highly accessible neighbourhoods. Figure 7 (b) displays the ISU university campus and illustrates a well accessible local environment. 


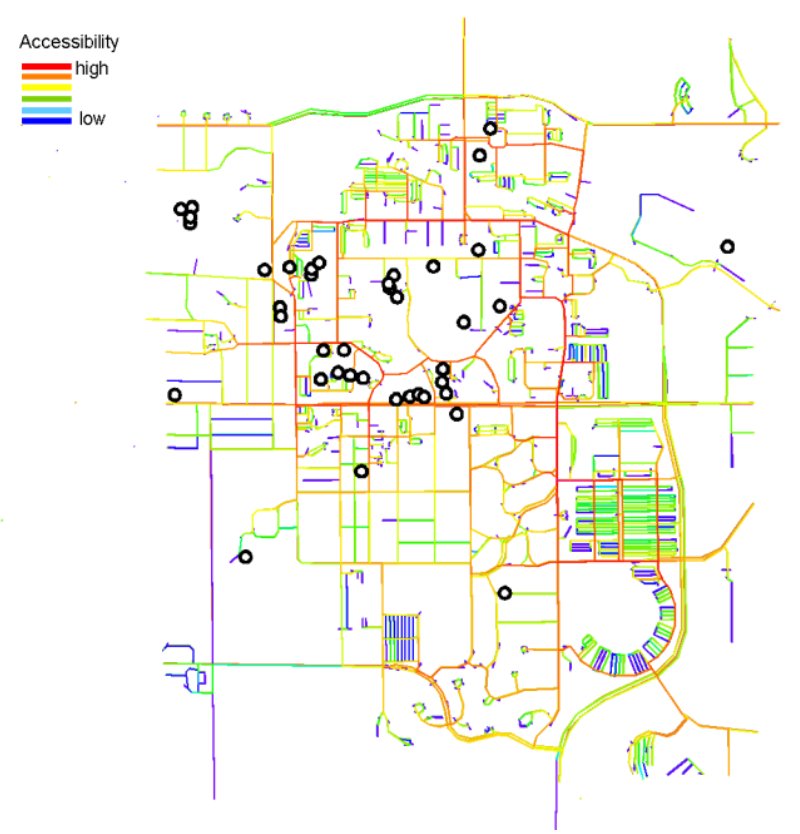

7(b) Zoom-in of the local potential through movement: Iowa State University Campus is a well accessible environment on a local scale.

Often campuses relate powerful local integration in the absence of global integration (Greene and Penn 1997). This contrasts with our case study of the university campus Ames. Both analyses show that the campus area is well related to the citywide global network. Figure 6(a) and (b) show the following connections: Lincoln Way to the south, Pammel Drive and N University Boulevard to the north and east, and N Hyland Avenue to the east) as well it incorporates a highly accessible local network. See also Figure 3 for the names of the major roads. Figure 7(a) and (b) demonstrate that the ISU campus is well connected to the city centre of Ames with shopping possibilities and amenities as also shown on Figure 6(a).

We argue that the functional aspects in relation to the spatial aspects are well balanced and therefore encourage a positive perception of the campus area, position that is further supported by the evidence collected from the map-based survey. It adds to the debate of creating healthy, sustainable, resilient and smart cities.

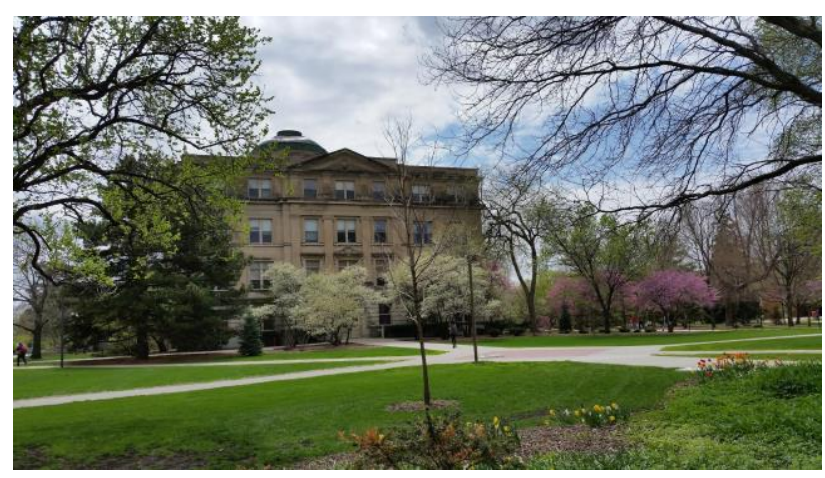

Figure 8. Iowa State University campus

Figure 8 shows a typical spring day in the Iowa State University campus. Many parts of the campus are walkable and there are no cars. The cars are parked in special dedicated parking lots. The campus includes big green areas and benches available for sitting and/or studying. The central library is the core of the campus.

\section{CONCLUSIONS AND FURTHER RESEARCH DIRECTIONS}

This paper summarizes our research on power places, places that evoke positive feelings and enable the citizens to recharge and relax. We combine a mapping experiment, which enabled us to collect data about power places, with space syntax analysis of the selected study area. In this research study, we selected the Iowa State University campus in the North American city of Ames, Iowa, as our main study case. The ISU campus represents a typical American university setting and it is located in a Midwestern North American town with a population of about 60,000 inhabitants. It serves as our first Northern American case study on power places.

The experimental method of mapping power places allowed us to gain a better understanding of public spaces in Ames, from the perspective of the students that live and study in this city. The majority of power places are, according to this small pilot survey, located in the proximity to parking infrastructure, shops and accessible road, bus and bike networks. Additional data collection is needed to be able to understand the role of green areas and parks. How often are they used by students and when? The space syntax analysis demonstrated that accessibility of the network - roads, bus and bike paths - is an important factor for the selection of power places.

The use of space syntax was especially useful to improve our understanding of the role that connectivity and networks have on the student's behavior, identified by their selection of the power places. Superimposing the network analysis over the map of power places additionally demonstrated the importance of accessibility to the network and the influence exerted by main roads and malls with their shopping possibilities.

In future research, we plan to improve the methodology for collecting data on power places. Improvements will include a more controlled experiment and the use of an online volunteered geographic information (VGI) platform, Maptionnaire. We intend to expand the space syntax analysis to include pedestrian models and a visual graph analysis for an in-depth understanding of additional characteristics of selected areas. Correlations of citywide and local measures, connectivity and visual links will give additional information regarding the relation between spatial configuration, mental maps and spatial atmosphere. The nature of visual structures is inherently connected to the construction of spatial atmosphere and perception. This in turn is linked to how citizens feel about places.

Our goal is to continue to study the perception of place, in particular power places, and how it relates to place-making and participatory design. Understanding how citizens feel about places, and why, will help create appropriate conditions for healthier, more pleasant and sustainable cities.

\section{ACKNOWLEDGEMENTS}

We would like to thank ISU graduate student Shoaib Mahmud for his assistance with the GIS mapping of the collected power places in Ames, Iowa.

\section{REFERENCES}

Al-Kodmany, K. (2001). Online tools for public participation. Government Information Quarterly 18: pp. 329-341. 
Basedow, S. and H. Pundt (2001). Braucht Bürgerbeteiligung in der Planung GIS-Funktionalitäten? CORP conference, Vienna, Austria.

Carver, S. (2001). The Future of Participatory Approaches Using Geographic Information: Developing a Research Agenda for the 21st Century, ESF-NSF Meeting on Access and Participatory Approaches in Using Geographic Information, Spoleto, Italy.

Cooper-Marcus, C. (1997). "Nature as healer: Therapeutic benefits in outdoor places." Nordisk Arkitekturforskning 1: 920.

Craig, W. J., Harris, T. M. and D. Weiner, Eds. (2002). Community Participation and Geographic Information Systems. London, Taylor \& Francis.

Georgiadou, Y. and J. Stoter (2010). "Studying the use of geoinformation in government - A conceptual framework." Computers, Environment and Urban Systems 34(1): 70-78.

Goodchild, M. F. (2007a). "Citizens as sensors: Web 2.0 and the volunteering of geographic information." Geofocus 7: 8-10.

Goodchild, M. F. (2007b). "Citizens as voluntary sensors: spatial data infrastructure in the world of Web 2.0

"International Journal of Spatial Data Infrastructures Research 2: 24-32.

Goodchild, M. F. (2007c). "Citizens as sensors: The world of volunteered geography." GeoJournal 69(4): 211-221.

Goodchild, M. F. (2011). Formalizing place in geographic information systems. Communities, Neighborhoods, and Health: Expanding the Boundaries of Place. L. M. Burton, Kemp, S. P., Leung, M.-C., Matthews, S. A., Takeuchi D. T. New York, Springer: p. 21-35.

Greene, M. and A. Penn (1997). "Socio-Spatial Analysis of Four University Campuses: The Implications of Spatial Configuration on Creation and Transmission of Knowledge." Proceedings, $1^{\text {st }}$ International Space Syntax Symposium London.

Haklay, M. (2010). "How good is volunteered geographical information? A comparative study of OpenStreetMap and Ordnance Survey datasets." Environment and Planning B 37(4): $682-703$

Haklay, M. and C. Tobón (2003). "Usability Engineering and PP GIS: towards a Learning-improving Cycle." International Journal of Geographical Information Science (IJGIS) 17(6): 577-592.

Hillier, B. (1996). "Space is the machine. A configurational theory of architecture." Cambridge: Cambridge University Press.

Hillier, B. (2001). "The theory of the city as object or how spatial laws mediate the social construction of urban space."Proceedings, $3^{\text {rd }}$ International Space Syntax Symposium Brasilia: 56.1-56.16

Hillier, B. (2009). "The Now and the Future of Space Syntax: From structures and models to theory". Keynote speech, $9^{\text {th }}$ International Space Syntax Symposium Seoul.
Hillier, B. and J. Hanson (1984). "The Social Logic of Space". Cambridge: Cambridge University Press

Hillier, B. , A. Turner, T. Yang, H.T. Park (2007). "Metric and topo-geometric properties of urban street networks",

Proceedings, $6^{\text {th }}$ International Space Syntax Symposium Istanbul.

Jankowski, P. and T. Nyerges (2001). Geographic Information Systems for Group Decision Making, Taylor \& Francis.

Kingston, R., Carver, S., Evans, A. and I. Turton (1999) Virtual Decision Making in Spatial Planning: Web-based Geographical Information Systems for Public Participation in Environmental Decision Making. online available at:

http://www.geog.leeds.ac.uk/papers/99-9/, accessed: 08/08/2017.

Kingston, R., Carver, S., Evans, A. and I. Turton (2000). "Webbased public participation geographical information systems: an aid to local environmental decision-making." Computers, Environment and Urban Systems 24: 109-125.

Korpela, K. (1992). "Adolescents' favourite places and environmental self-regulation " Journal of Environmental Psychology 12: 249-258.

Korpela, K. (2012). Place attachment. The Oxford Handbook of Environmental and Conservation Psychology. S. Clayton. New York, Oxford University Press: 148-163.

Korpela, K. and T. Hartig (1996). "Resotrative Qualities of Places." Journal of Environmental Psychology 16: 221-233

Korpela, K. M. (1998). "Place-ident ity as a product of environment self-regulation." Journal of Environmental Psychology 9(241-256).

Korpela, K. M., Harting, T., Kaiser, F.G., Fuhrer, U. (2001). "Restorative Experience and Self-Regulation in Favorite Places." Environment and Behavior 33(572): The online version of this article can be found at: http://eab.sagepub.com/content/33/34/572.

Neuman, D. (2003). "Campus planning". In: D. Neuam (ed.) "Building tpe Basis for College and University Facilities."New Jersey: John Wiley \& Sons: 1-43.

Pickles, J. (1995). Representations in an electronic age: geography, GIS, and democracy. Ground truth: the social implications of geographic information systems. J. Pickles. New York, Guilford Press: 1-30.

Poplin, A. (2012). "Web-based PPGIS for Wilhelmsburg, Germany: an Integration of Interactive GIS-based Maps with an Online Questionnaire." Special Issue of the Journal of Urban and Regional Information Systems Association (URISA), 25(2): 71-84.

Poplin, A. (2015). How User-Friendly are Online Interactive Maps? Survey Based on Experiments with Heterogeneous Users." Cartography and Geographic Information Science 42(4): 358-376

Poplin, A. (2017 ). "Mapping Expressed Emotions: Empirical Experiments on Power Places: Experiments with Maps." Journal of Cartography and Geographic Information, Volume 2, p. 83-91. 
Rinner, C. (1999). Argumentation Maps - GIS-based Discussion Support for Online Planning. GMD Research Series No. 22. Sankt Augustin, Germany, GMD German National Research Center for Information Technology.

Schlossberg, M. and E. Shuford (2005). "Delineating "Public" and "Participation" in PP GIS." URISA Journal 16(2): 16-26.

Schroeder, P. (1996). Report on Public Participation GIS Workshop, NCGIA Technical Report 96-97, Scientific Report for Initiative 19 Specialist Meeting.

Shenk, L., Anderson, N. and U. Passe (2016). Engaged science and working with youth for sustainable cities: A partnership between "East High Cares" and an Iowa State University research team. Confronting the Challenges of Public Participation: Issues in Environmental, Planning and Health Decision-Making, Ames, Iowa, USA, Charleston, SC: CreateSpace.

Shenk, L., Krejci, C., M. Dorneich, U. Passe, W. Huang and J. Stonewall (2017). When the humanities partner with engineering and design for community capacity-building: Codesigning a community's story of weatherization using agentbased modeling. Community Development Society Conference, Big Sky, Montana.

Sieber, R. (2006). "Public Participaton Geographic Information Systems: A Literature Review and Framework." Annals of the Association of American Geographers 96(3): 491-507.

Steinmann, R., Krek A. and T. Blaschke (2004). Can Online Map-Based Applications Improve Citizen Participation? . Lecture Notes in Computer Science, TED on e-government 2004. Bozen, Italy, Springer Verlag.

Talen, E. (1999). "Constructing Neighbourhoods from the Bottom Up: the Case for Resident Generated GIS." Environment and Planning B 26: 533-555.

Thompson, M. M. (2000). "GIS Technology and Data Sharing, Planning into the Next Millennium." Cornell Journal of Planning and Urban Issues 15: 20-33.

Turner, P.V. (1987). "Campus: An American Planning Tradition."New York: Architectural History Foundation.

van Nes, A. and C. Yamu (in print). "Configurational Analysis: A method to measure urban space related to social, economic and cognitive factors." In: C. Yamu, A. Poplin, O. Dewisch, G. de Roo (eds. (in print)) "The Virtual and The Real in Urban Planning and Design: Perspectives, Practices and Applications." New York and London: Routledge Publishing.

Yamu, C. (2014). "It Is Simply Complex(ity). Modelling and Simulation in the Light of Decision-Making, Emergent Structures and a World of Non-Linearity."disP - The Planning Review 50(4): 43-53.

Yamu, C. and A. Voigt (2011). "Strategic Planning and Design with Space Syntax". Proceedings, eCAADe - Education and Research in Computer Aided Architectural Design in Europe Conference, Ljubljana, 125-133.
Yaylali-Yildiz, B., C. Yamu and E. Cil (2013). "Exploring the effects of spatial and social segregation in university campuses, IZTECH as a case study."Urban Design International, online: 119, doi:10.1057/udi.2013.19.

Winter, S. and C. Freksa (2012). "Approaching the Notions of Place by Contrast." Journal of Spatial Information Science 5: p. $31-50$. 